\title{
Gene-Diet Interaction between SIRT6 and Soybean Intake for Different Levels of Pulse Wave Velocity
}

\section{Kexin Sun ${ }^{1}$, Xiao Xiang ${ }^{1}$, $\mathrm{Na} \mathrm{Li}^{2}$, Shaoping Huang ${ }^{2}$, Xueying Qin ${ }^{1}$, Yiqun Wu ${ }^{1}$, Xun Tang ${ }^{1}$, Pei Gao ${ }^{1}$, Jing Li ${ }^{1}$, Tao Wu ${ }^{1}$, Dafang Chen ${ }^{1}$ and Yonghua $\mathrm{Hu}^{1, *}$}

1 Department of Epidemiology and Biostatistics, Peking University Health Science Center, 38 Xueyuan Road, Beijing 100191, China; E-Mails: kexin_sun@bjmu.edu.cn (K.S.); doublex1990@live.cn (X.X.); xueyingqin@gmail.com (X.Q.); qywu118@163.com (Y.W.); tangxun@bjmu.edu.cn (X.T.); pei.gao@163.com (P.G.); jing2k9@gmail.com (J.L.); twu@bjmu.edu.cn (T.W.); dafangchen@bjmu.edu.cn (D.C.)

2 Fangshan District Center for Disease Control and Prevention, Beijing 102401, China; E-Mails: sophia8063@163.com (N.L.); fshcdcmb@yeah.net (S.H.)

* Author to whom correspondence should be addressed; E-Mail: yhhu@bjmu.edu.cn; Tel./Fax: +86-10-8280-1189.

Academic Editor: Ritva Tikkanen

Received: 27 April 2015 / Accepted: 19 June 2015 / Published: 24 June 2015

Abstract: Soybean is a common food for the Chinese people. We aimed to investigate the risk for brachial ankle pulse wave velocity (baPWV) with inflammatory-related SNPs and soybean. baPWV was measured, and 16 inflammatory-related SNPs located on $A D I P O Q$, CDH13, SIRT3, SIRT6, CXCL12, CXCR4, NOS1, PON1 and CDKN2B were genotyped in 1749 Chinese participants recruited from various communities. ADIPOQ rs12495941 (GT/TT vs. GG: crude OR $=1.27, p=0.044)$ and SIRT6 rs107251 (CT/TT vs. CC: crude $\mathrm{OR}=0.74, p=0.009)$ were associated with abnormal baPWV $(\mathrm{baPWV} \geq 1700 \mathrm{~cm} / \mathrm{s})$. After adjustment for conventional environmental risk factors, rs12495941 was associated with abnormal baPWV (GT/TT $v s$. GG: adjusted OR $=1.43, p=0.011)$, but the association between rs107251 and abnormal baPWV was not significant (CT/TT vs. CC: adjusted $\mathrm{OR}=0.83, p=0.173)$. The interaction between $\mathrm{rs} 107251$ and soybean intake for different levels of baPWV was statistically significant $(p=0.017)$. Compared with a high level of soybean intake, a low level of soybean intake can significantly decrease the risk of abnormal baPWV in individuals of rs107251 CT/TT genotypes $(\leq 100$ vs. $>100 \mathrm{~g} /$ week: adjusted $\mathrm{OR}=0.542, p=0.003$ ). In this study, associations between $A D I P O Q \mathrm{rs} 12495941$, 
SIRT6 rs107251 and baPWV, as well as an interaction between SIRT6 rs107251 and soybean intake for different levels of baPWV were found.

Keywords: brachial ankle pulse wave velocity; atherosclerosis; genetic polymorphisms; inflammation; ADIPOQ; SIRT6; soybean; interaction

\section{Introduction}

Pulse wave velocity (PWV) is the speed at which the pulse wave propagates from heart to peripheral arteries [1]. It is widely used in clinical practice as a good surrogate marker of atherosclerosis [2]. A high pulse wave velocity indicates worsening arterial stiffness, which further implies a higher probability of atherosclerosis [3]. Atherosclerosis is known as a chronic inflammatory disease [4-7]. Genome-wide association studies (GWAS) focused on it have successfully identified numerous disease-associated SNPs located on inflammatory-related genes [8], such as 9p21 [9-11] and CXCL12 [11]. The links between atherosclerosis and other inflammatory-related genes also have attracted much attention. Adiponectin is involved in regulating glucolipid metabolism and anti-inflammatory and antiatherogenic responses in the vascular system [12-14]. Cadherin 13 $(C D H 13)$ is an adiponectin receptor expressed in endothelial and smooth muscle cells $[15,16]$. The sirtuins (SIRT) are a family of highly-conserved nicotinamide adenine dinucleotide (NAD) ${ }^{+}$-dependent enzymes [17]. SIRT3 and SIRT6 have diverse biological functions in DNA repair processes, glucolipid metabolism and inflammation responses [18-20] and are suggested to have an impact on cardiovascular diseases (CVD), cancer and aging [21]. CXCR4 is the receptor of CXCL12. The $C X C L 12 / C X C R 4$ axis plays an important role in atherogenesis [22]. The nitric oxide synthase 1 (NOS1) enzyme can affect the synthesis of NO (nitric oxide), which is involved in the pathogenesis of atherosclerosis [23]. Paraoxonase 1 (PON1) protects against atherosclerosis by preventing the oxidation of blood lipids [24]. These markers contribute to the initiation, propagation and activation of lesions in the arterial wall through different biologic pathways. In addition, atherosclerosis can also be affected by various environmental factors, such as exercise and diet [25,26]. Soybean is a common dish on Chinese dinner tables. Its nutritional value varies for different disease outcomes. It was reported that a soybean diet has a preventive effect on atherosclerosis [27]. However, whether soybean intake interacts with genetic polymorphisms for atherosclerosis was not clear.

Brachial ankle PWV (baPWV) calculates PWV using the pulse waves of brachial arteries and ankle arteries [28]. baPWV is significantly correlated with other surrogate markers of atherosclerosis, such as flow-mediated dilation (FMD) of brachial artery and carotid intima-media thickness (cIMT) [29]. In this study, we used baPWV as an independent predictor for atherosclerosis and chose 16 inflammatory-related SNPs located on ADIPOQ, CDH13, SIRT3, SIRT6, CXCL12, CXCR4, NOS1, $P O N 1$ and $C D K N 2 B$ using a candidate gene approach. The aims of this cross-sectional study were to: (1) identify those associated with baPWV among the chosen 16 candidate SNPs; (2) explore the association between soybean intake and baPWV; and (3) explore the interactions between soybean intake and selected SNPs in the first step for abnormally high baPWV. 


\section{Results}

\subsection{The Associations between Genetic Variations and baPWV}

A total of 1749 Chinese Han participants were involved in the analysis. The average age was $58.3 \pm 10.0$ years old. Of the participants, $880(50.3 \%)$ were male. Sixteen SNPs located on nine inflammation-related genes were genotyped. The associations between SNPs and baPWV were analyzed under additive, recessive and dominant models. The ADIPOQ rs12495941 polymorphism was significantly associated with baPWV under the dominant model. Compared with the GG genotype, the combined group of GT and TT genotypes (GT/TT) was positively associated with abnormal baPWV $(\geq 1700 \mathrm{~cm} / \mathrm{s})(\mathrm{GT} / \mathrm{TT}$ vs. GG: OR $=1.27, p=0.044)$. The SIRT6 rs 107251 polymorphism was significantly associated with abnormal baPWV under additive (per $\mathrm{T}$ allele: $\mathrm{OR}=0.77, p=0.004)$ and dominant models (CT/TT $v s . \mathrm{CC}: \mathrm{OR}=0.74, p=0.009)$. These two SNPs were supposed to have influences on baPWV and were involved in the further analysis (Table 1).

Table 1. The associations between 16 inflammation-related SNPs and brachial ankle pulse wave velocity (baPWV).

\begin{tabular}{|c|c|c|c|c|c|c|c|c|c|}
\hline \multirow{2}{*}{ SNP ID } & \multirow{2}{*}{ Chr } & \multirow{2}{*}{ Gene } & \multirow{2}{*}{ Alleles } & \multirow{2}{*}{$\begin{array}{c}\text { Reference } \\
\text { Allele }\end{array}$} & \multirow{2}{*}{ MAF } & \multirow{2}{*}{$\begin{array}{c}\text { HWE } \\
p \text {-Value }\end{array}$} & \multicolumn{3}{|c|}{$p$-Value } \\
\hline & & & & & & & Additive & Dominant & Recessive \\
\hline rs 2228014 & 2 & CXCR4 & $\mathrm{C} / \mathrm{T}$ & $\mathrm{C}$ & $\mathrm{T}(0.13)$ & 0.691 & 0.591 & 0.879 & 0.151 \\
\hline rs182052 & 3 & $A D I P O Q$ & $\mathrm{G} / \mathrm{A}$ & G & A $(0.47)$ & 0.788 & 0.335 & 0.595 & 0.286 \\
\hline rs12495941 & 3 & $A D I P O Q$ & $\mathrm{G} / \mathrm{T}$ & G & $\mathrm{T}(0.38)$ & 0.458 & 0.205 & 0.044 & 0.715 \\
\hline rs662 & 7 & PON1 & $\mathrm{G} / \mathrm{A}$ & G & $\mathrm{A}(0.37)$ & 0.884 & 0.677 & 0.622 & 0.898 \\
\hline rs3735590 & 7 & PON1 & $\mathrm{C} / \mathrm{T}$ & $\mathrm{C}$ & $\mathrm{T}(0.14)$ & 0.866 & 0.545 & 0.439 & 0.796 \\
\hline rs1333040 & 9 & $C D K N 2 B$ & $\mathrm{~T} / \mathrm{C}$ & $\mathrm{T}$ & $\mathrm{C}(0.29)$ & 0.822 & 0.945 & 0.724 & 0.631 \\
\hline rs2383207 & 9 & $C D K N 2 B$ & $\mathrm{G} / \mathrm{A}$ & G & $\mathrm{A}(0.33)$ & 0.860 & 0.983 & 0.461 & 0.251 \\
\hline rs2383206 & 9 & $C D K N 2 B$ & $\mathrm{~A} / \mathrm{G}$ & A & $\mathrm{G}(0.47)$ & 0.658 & 0.701 & 0.450 & 0.875 \\
\hline rs2297630 & 10 & CXCL12 & $\mathrm{G} / \mathrm{A}$ & G & A $(0.14)$ & 0.676 & 0.896 & 0.880 & 0.356 \\
\hline rs1801157 & 10 & CXCL12 & $\mathrm{G} / \mathrm{A}$ & G & $\mathrm{A}(0.23)$ & 0.513 & 0.531 & 0.980 & 0.056 \\
\hline rs3825075 & 11 & SIRT3 & $\mathrm{A} / \mathrm{G}$ & A & $\mathrm{G}(0.41)$ & 0.777 & 0.483 & 0.849 & 0.290 \\
\hline rs2293050 & 12 & NOS1 & $\mathrm{G} / \mathrm{A}$ & G & $\mathrm{A}(0.45)$ & 0.587 & 0.086 & 0.258 & 0.089 \\
\hline rs6565105 & 16 & CDH13 & $\mathrm{G} / \mathrm{A}$ & G & $\mathrm{A}(0.40)$ & 0.911 & 0.269 & 0.298 & 0.466 \\
\hline rs1048612 & 16 & $\mathrm{CDH13}$ & $\mathrm{C} / \mathrm{T}$ & $\mathrm{C}$ & $\mathrm{T}(0.19)$ & 0.617 & 0.688 & 0.563 & 0.727 \\
\hline rs3865188 & 16 & CDH13 & $\mathrm{T} / \mathrm{A}$ & $\mathrm{T}$ & $\mathrm{A}(0.33)$ & 0.785 & 0.539 & 0.646 & 0.565 \\
\hline rs 107251 & 19 & SIRT6 & $\mathrm{C} / \mathrm{T}$ & $\mathrm{C}$ & $\mathrm{T}(0.29)$ & 0.965 & 0.004 & 0.009 & 0.052 \\
\hline
\end{tabular}

Chr: chromosome; alleles: major allele/minor allele; MAF: minor allele (minor allele frequency);

HWE: Hardy-Weinberger equilibrium; additive: $p$-values under additive models; dominant: $p$-values under dominant models; recessive: $p$-values under recessive models; the significance level for $p$-values was 0.05 .

\section{2. baPWV Depending on ADIPOQ rs 12495941, SIRT6 rs 107251 Polymorphisms and Different} Levels of Soybean Intake

After adjustment for conventional environmental risk factors, as shown in Table 2, the $A D I P O Q$ rs12495941 polymorphism was significantly associated with abnormal baPWV under additive (per T allele: $\mathrm{OR}=1.23, p=0.040)$ and dominant models (GT/TT $v s . \mathrm{GG}$ : $\mathrm{OR}=1.43, p=0.011$ ). 
However, the association between the SIRT6 rs107251 polymorphism and abnormal baPWV was not significant after adjustment for conventional environmental risk factors (per $\mathrm{T}$ allele: adjusted $\mathrm{OR}=0.85, p=0.128 ; \mathrm{CT} / \mathrm{TT}$ vs. $\mathrm{CC}: \mathrm{OR}=0.83, p=0.173)$. Levels of soybean intake were not associated with baPWV after adjustment for conventional environmental risk factors $(\leq 100 \mathrm{vs}$. $>100 \mathrm{~g} /$ week: $\mathrm{OR}=0.95, p=0.629)$. The interaction between gender and soybean intake for different levels of baPWV was not significant $(p=0.768)$. (Table 2$)$.

Table 2. Associations between and ADIPOQ rs12495941 and SIRT6 rs107251 polymorphisms or levels of soybean intake baPWV.

\begin{tabular}{|c|c|c|c|c|}
\hline \multirow{2}{*}{ Factors } & \multicolumn{2}{|c|}{ baPWV n (\%) } & \multirow{2}{*}{ OR * $(95 \% \mathrm{CI})$} & \multirow{2}{*}{$p$} \\
\hline & $\geq 1700 \mathrm{~cm} / \mathrm{s}$ & $<1700 \mathrm{~cm} / \mathrm{s}$ & & \\
\hline \multicolumn{5}{|c|}{$A D I P O Q$ rs12495941^ } \\
\hline GG & $222(33.7)$ & $437(66.3)$ & Ref & - \\
\hline GT/TT & $393(36.1)$ & $697(63.9)$ & $1.43(1.09-1.88)$ & 0.011 \\
\hline Per T Allele & - & - & $1.23(1.01-1.50)$ & 0.040 \\
\hline \multicolumn{5}{|c|}{ SIRT6 rs107251 \# } \\
\hline $\mathrm{CC}$ & $344(37.8)$ & $566(62.2)$ & Ref & - \\
\hline $\mathrm{CT} / \mathrm{TT}$ & $271(32.3)$ & $568(67.7)$ & $0.83(0.64-1.09)$ & 0.173 \\
\hline Per T Allele & - & - & $0.85(0.68-1.05)$ & 0.128 \\
\hline \multicolumn{5}{|l|}{ Soybean Intake } \\
\hline$>100 \mathrm{~g} /$ week & $252(35.2)$ & $463(64.8)$ & Ref & - \\
\hline$\leq 100 \mathrm{~g} /$ week & $363(35.1)$ & $671(64.9)$ & $0.95(0.77-1.17)$ & 0.629 \\
\hline
\end{tabular}

* Adjustment for age, gender, smoking status, drinking status, BMI, FBG, SBP, TG, HDL-C, vegetables and fruit intake, meat egg and milk intake, cereal intake and moderate-intensity exercise; ${ }^{\wedge}$ rs12495941: GG was the reference genotype, and G was the major allele. GT/TT represents the combined group of GT and TT genotypes and so does CT/TT; ${ }^{\#}$ rs107251: CC was the reference genotype, and C was the major allele; Ref: reference group.

\subsection{Anthropometric, Lifestyle Characteristics and Biochemical Indices Depending on ADIPOQ} rs 12495941 and SIRT6 rs107251 Polymorphisms

There were no significant differences for the anthropometric, lifestyle or biochemical indices for different genotypes of SIRT6 or ADIPOQ (Table 3). 
Table 3. Anthropometric, lifestyle characteristics and biochemical indices of all participants depending on SIRT6 rs 107251 and ADIPOQ rs12495941 genotypes *.

\begin{tabular}{|c|c|c|c|c|c|c|c|c|}
\hline \multirow{2}{*}{ Characteristics } & \multicolumn{3}{|c|}{ SIRT6 rs107251 } & \multirow{2}{*}{$p$} & \multicolumn{3}{|c|}{$A D I P O Q$ rs12495941 } & \multirow{2}{*}{$p$} \\
\hline & $\mathbf{C C}$ & CT & TT & & GG & GT & TT & \\
\hline$n$ & 910 & 722 & 117 & - & 659 & 853 & 237 & \\
\hline Age & $58.5 \pm 9.8$ & $57.9 \pm 10.2$ & $59.1 \pm 10.6$ & 0.292 & $58.6 \pm 9.9$ & $58.2 \pm 10.0$ & $57.7 \pm 10.4$ & 0.579 \\
\hline Male, $n(\%)$ & $464(51.0)$ & $361(50.0)$ & $55(47.0)$ & 0.703 & $345(52.4)$ & $416(48.8)$ & $119(50.2)$ & 0.385 \\
\hline Education, $n(\%)$ & & & & 0.630 & & & & 0.483 \\
\hline$<9$ years & $299(32.8)$ & $259(35.9)$ & $45(38.5)$ & & $239(36.3)$ & $281(30.0)$ & $83(35.0)$ & \\
\hline $9-12$ years & $432(47.5)$ & $331(45.8)$ & $51(43.6)$ & & $307(46.6)$ & $402(47.1)$ & $105(44.3)$ & \\
\hline$>12$ years & $179(19.7)$ & $132(18.3)$ & $21(17.9)$ & & $113(17.1)$ & $170(19.9)$ & $49(20.7)$ & \\
\hline Smoke, $n(\%)$ & $402(44.2)$ & $341(47.2)$ & $53(45.3)$ & 0.461 & $317(48.1)$ & $367(43.0)$ & $112(47.3)$ & 0.146 \\
\hline Drink, $n(\%)$ & $280(30.8)$ & $221(30.6)$ & $31(26.5)$ & 0.655 & $196(29.7)$ & $262(30.7)$ & $74(31.2)$ & 0.901 \\
\hline Soybean Intake, $n(\%)$ & & & & 0.505 & & & & 0.594 \\
\hline$>100 \mathrm{~g} /$ week & $378(41.5)$ & $295(40.9)$ & $42(35.9)$ & & $265(40.2)$ & $346(40.6)$ & $104(43.9)$ & \\
\hline$\leq 100 \mathrm{~g} /$ week & $532(58.5)$ & $427(59.1)$ & $75(64.1)$ & & $394(59.8)$ & $507(59.4)$ & $133(56.1)$ & \\
\hline $\begin{array}{c}\text { Vegetables and } \\
\text { Fruit Intake, } n(\%)\end{array}$ & & & & 0.569 & & & & 0.937 \\
\hline$<470 \mathrm{~g} /$ day & $458(50.3)$ & $380(52.6)$ & $63(53.8)$ & & $341(51.7)$ & $436(51.1)$ & $124(52.3)$ & \\
\hline$\geq 470 \mathrm{~g} /$ day & $452(49.7)$ & $342(47.4)$ & $54(46.2)$ & & $318(48.3)$ & $417(48.9)$ & $113(47.7)$ & \\
\hline $\begin{array}{c}\text { Meat Egg and } \\
\text { Milk Intake, } n(\%)\end{array}$ & & & & 0.231 & & & & 0.218 \\
\hline$<130 \mathrm{~g} /$ day & $458(50.3)$ & $386(53.5)$ & $67(57.3)$ & & $357(54.2)$ & $441(51.7)$ & $113(47.7)$ & \\
\hline$\geq 130 \mathrm{~g} /$ day & $452(49.7)$ & $336(46.5)$ & $50(42.7)$ & & $302(45.8)$ & $412(48.3)$ & $124(52.3)$ & \\
\hline Cereal Intake, $n(\%)$ & & & & 0.945 & & & & 0.485 \\
\hline$<400$ g/day & $425(46.7)$ & $334(46.3)$ & $56(47.9)$ & & $295(44.8)$ & $406(47.6)$ & $114(48.1)$ & \\
\hline$\geq 400 \mathrm{~g} /$ day & $485(53.3)$ & $388(53.7)$ & $61(52.1)$ & & $364(55.2)$ & $447(52.4)$ & $123(51.9)$ & \\
\hline
\end{tabular}


Table 3. Cont.

\begin{tabular}{|c|c|c|c|c|c|c|c|c|}
\hline \multirow{2}{*}{ Characteristics } & \multicolumn{3}{|c|}{ SIRT6 rs107251 } & \multirow[b]{2}{*}{$p$} & \multicolumn{3}{|c|}{$A D I P O Q$ rs12495941 } & \multirow[b]{2}{*}{$p$} \\
\hline & $\mathrm{CC}$ & CT & TT & & GG & GT & TT & \\
\hline $\begin{array}{l}\text { Moderate-Intensity } \\
\text { Exercise, } \boldsymbol{n}(\%)\end{array}$ & & & & 0.347 & & & & 0.067 \\
\hline$<60 \mathrm{~min} /$ week & $447(49.1)$ & $330(45.7)$ & $53(45.3)$ & & $314(47.6)$ & $388(45.5)$ & $128(54.0)$ & \\
\hline$\geq 60 \mathrm{~min} /$ week & $463(50.9)$ & $392(54.3)$ & $64(54.7)$ & & $345(52.4)$ & $465(54.5)$ & $109(46.0)$ & \\
\hline $\mathrm{BMI} / \mathrm{kg} / \mathrm{m}^{2}$ & $26.2 \pm 3.8$ & $26.1 \pm 3.9$ & $26.3 \pm 4.1$ & 0.931 & $26.0 \pm 3.7$ & $26.3 \pm 4.0$ & $26.1 \pm 4.0$ & 0.379 \\
\hline FBG/mmol/L & $5.75 \pm 2.23$ & $5.82 \pm 3.12$ & $5.69 \pm 2.47$ & 0.827 & $5.9 \pm 3.2$ & $5.7 \pm 2.3$ & $5.7 \pm 2.2$ & 0.444 \\
\hline $\mathrm{SBP} / \mathbf{m m H g}$ & $141.7 \pm 20.9$ & $139.2 \pm 21.4$ & $139.9 \pm 20.3$ & 0.057 & $141.6 \pm 26.0$ & $140.7 \pm 21.8$ & $139.8 \pm 20.7$ & 0.524 \\
\hline DBP/mmHg & $82.9 \pm 16.1$ & $81.7 \pm 12.0$ & $80.8 \pm 10.1$ & 0.052 & $81.9 \pm 19.3$ & $83.0 \pm 16.4$ & $83.6 \pm 11.5$ & 0.294 \\
\hline $\mathrm{TC} / \mathrm{mol} / \mathrm{L}$ & $3.37 \pm 0.94$ & $3.30 \pm 0.79$ & $3.34 \pm 0.98$ & 0.275 & $3.32 \pm 0.95$ & $3.34 \pm 0.83$ & $3.36 \pm 0.90$ & 0.825 \\
\hline TG/mmol/L & $1.81 \pm 1.37$ & $1.74 \pm 1.47$ & $1.80 \pm 1.28$ & 0.626 & $1.75 \pm 1.56$ & $1.78 \pm 1.28$ & $1.83 \pm 1.41$ & 0.783 \\
\hline HDL-C/mmol/L & $1.14 \pm 0.30$ & $1.07 \pm 0.35$ & $1.01 \pm 0.25$ & 0.653 & $1.05 \pm 0.28$ & $1.06 \pm 0.68$ & $1.07 \pm 0.30$ & 0.540 \\
\hline LDL-C/mmol/L & $2.68 \pm 0.81$ & $2.67 \pm 0.78$ & $2.64 \pm 0.77$ & 0.869 & $0.79 \pm 0.03$ & $0.81 \pm 0.03$ & $0.79 \pm 0.05$ & 0.440 \\
\hline
\end{tabular}

* Continuous variables were described as the mean \pm standard deviation. Categorical variables were described as frequency (proportion); BMI: body mass index; FBG: fasting blood glucose; SBP: systolic blood pressure; DBP: diastolic blood pressure; TC: total cholesterol; TG: total triglycerides; HDL-C: high-density lipoprotein cholesterol; LDL-C: low-density lipoprotein cholesterol. 


\subsection{Interactions between ADIPOQ rs 12495941 and SIRT6 rs 107251 Polymorphisms and Soybean} Intake for Different Levels of baPWV

No interactions were found between $A D I P O Q$ rs12495941 and soybean intake for different levels of baPWV in all participants $(p=0.800)$. However, a multiplicative interaction was found between SIRT6 rs107251 and soybean intake in all participants $(\mathrm{OR}=0.514, p=0.017)$, which indicated that the effect of soybean intake on baPWV differed depending on the SIRT6 rs 107251 genotypes. For individuals of the rs107251 CT/TT genotypes, low soybean intake can significantly decrease the risk of abnormal baPWV ( $\leq 100 v s .>100 \mathrm{~g} /$ week: adjusted $\mathrm{OR}=0.542, p=0.003)$. (Table 4). After stratification by gender, the interaction between rs107251 and soybean intake continued to be significant in males $(p=0.033)$ but not in females $(p=0.122)$.

Table 4. Interactions between $A D I P O Q$ rs12495941 and SIRT6 rs107251 polymorphisms and soybean intake for different levels of baPWV.

\begin{tabular}{|c|c|c|c|c|c|c|}
\hline \multirow{2}{*}{ Genotypes } & \multirow{2}{*}{ Soybean Intake } & \multicolumn{2}{|c|}{ baPWV n (\%) } & \multirow{2}{*}{ OR * $(95 \%$ CI $)$} & \multirow{2}{*}{$p$} & \multirow{2}{*}{$\begin{array}{c}\text { Interaction } \\
p \text {-Value }\end{array}$} \\
\hline & & $\geq 1700 \mathrm{~cm} / \mathrm{s}$ & $<1700 \mathrm{~cm} / \mathrm{s}$ & & & \\
\hline \multicolumn{7}{|c|}{ 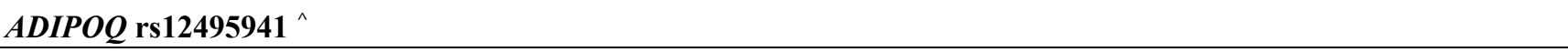 } \\
\hline GG & $>100 \mathrm{~g} /$ week & $89(33.6)$ & $176(66.4)$ & Ref & - & \multirow{4}{*}{0.800} \\
\hline \multirow{3}{*}{ GT/TT } & $\leq 100 \mathrm{~g} /$ week & $133(33.8)$ & $261(66.2)$ & $0.96(0.69-1.39)$ & 0.232 & \\
\hline & $>100 \mathrm{~g} /$ week & $163(36.2)$ & $287(63.8)$ & $1.37(0.89-2.11)$ & 0.159 & \\
\hline & $\leq 100 \mathrm{~g} /$ week & $230(35.9)$ & $410(64.1)$ & $1.12(0.74-1.69)$ & 0.596 & \\
\hline \multicolumn{7}{|c|}{ SIRT6 rs107251 \# } \\
\hline \multirow[t]{2}{*}{$\mathrm{CC}$} & $>100 \mathrm{~g} /$ week & $137(36.2)$ & $241(63.8)$ & Ref & - & \multirow{4}{*}{0.017} \\
\hline & $\leq 100 \mathrm{~g} /$ week & 207 (38.9) & $325(61.1)$ & $1.07(0.74-1.56)$ & 0.707 & \\
\hline \multirow[t]{2}{*}{ CT/TT } & $>100 \mathrm{~g} /$ week & $115(34.1)$ & $222(65.9)$ & $1.23(0.81-1.88)$ & 0.326 & \\
\hline & $\leq 100 \mathrm{~g} /$ week & $156(31.1)$ & $346(68.9)$ & $0.68(0.46-1.01)$ & 0.055 & \\
\hline
\end{tabular}

* Adjustment for age, gender, smoking status, drinking status, BMI, FBG, SBP, TG, HDL-C, vegetables and fruit intake, meat egg and milk intake, cereal intake and moderate-intensity exercise; ^ rs12495941: GG was the reference genotype, and $\mathrm{G}$ was the major allele. GT/TT represents the combined group of GT and TT genotypes and so does CT/TT; \# rs107251: CC was the reference genotype, and $\mathrm{C}$ was the major allele; the interaction between rs107251 and soybean: in males: $\mathrm{OR}=0.431, p=0.033$; in females: $\mathrm{OR}=0.528$, $p=0.122$; Ref: reference group.

\section{Discussion}

In the present candidate gene study, we evaluated the associations between 16 SNPs located on nine different inflammatory-related genes and baPWV. Among 16 SNPs, ADIPOQ rs12495941 and SIRT6 rs107251 were associated with abnormal baPWV and were selected for the further analysis about the interactions. A multiplicative interaction was observed between SIRT6 rs107251 and soybean intake, which indicated that the effect of soybean intake on baPWV differed depending on different genotypes of rs 107251.

$A D I P O Q$ rs12495941 is located in the intron 1 region, which was suggested to be associated with the risk factors for atherosclerosis, i.e., adiponectin level [30], type 2 diabetes [31], body weight and waist and hip circumferences [31,32]. Since baPWV is a good surrogate marker of atherosclerosis, 
the association between rs12495941 and baPWV may partially be due to the relationship with these risk factors. The SIRT6 gene is located on chromosome 19 (19p13.3). Full-length human SIRT6 is a broadly-expressed, predominantly nuclear protein containing 355 amino acid residues [33]. SIRT6 may influence the development of CVDs in several ways: (1) impact glycolipid homeostasis by controlling the expression of multiple related metabolic genes [21,34,35]; (2) Negatively regulate cardiac hypertrophy by attenuating insulin-like growth factor (IGF)-Akt signaling and, thus, impacting the development of heart failure [20]; (3) SIRT6 is a critical regulator of vascular smooth muscle cell differentiation, which contributes to atherosclerosis [36]. rs107251 is an intron variant, which might be in linkage disequilibrium with the neighboring functional variant. TenNapel et al. [37] suggested that the CC or CT genotype at rs107251 displayed a more than five-year survival advantage compared to the TT genotype. Another study observed that T carriers of rs107251 had an increased risk for carotid plaque [38]. However, the current study suggested that rs107251 CC was the risk genotype for abnormal baPWV, and this association was not significant after adjustment for conventional risk factors. We suspect that this difference might be due to the existence of population heterogeneity. The first two studies were based on a Caucasian population and a multiethnic population (67\% Caribbean Hispanic, $17 \%$ black and 15\% white), respectively, while our study was based on a Chinese Han population. The genotype distributions of HapMap-CEU and HapMap-CHB populations are different (T allele frequency: 0.142 vs. 0.367). The genotype distributions of HapMap-JPT (T allele frequency: 0.322) were closer to those of the HapMap-CHB population, and a study based on a Japanese population reported that there were no association between SIRT6 rs107251 T allele and diabetic nephropathy [39], which is a disease associated with atherosclerosis [40].

Though the biological functions of soy isoflavones, including prevention of osteoporosis [41], anti-photoaging effect [42] and anti-inflammatory activities [43], the association between soybean intake and different disease outcomes varied. The interactions between genetic polymorphisms and soybean intake were also reported. For example, high soy isoflavone intake may reduce the risk of breast cancer caused by $C Y P 1 B 1$ risk genotypes [44]. Additionally, it was inversely associated with endometrial cancer among $S H B G$ gene Asp/Asp carriers [45]. However, the UGT1A1 rs2070959 GG genotype and low soy food intake may decrease the risk of endometrial cancer [46]. In addition, the studies concerning combined gene-soybean effects for atherosclerosis or its risk factors are limited. Wang et al. [47] suggested people with the CT haplotype of rs3846662 and rs3846663 and low soybean intake had a higher risk of being overweight and obesity. A high level of soybean intake can significantly reduce the levels of TC and LDL-C only for BsmI rs1544410 GG genotype carriers [48]. To our knowledge, this is the first study to investigate the role of the combined effect of SIRT6 rs107251 and soybean for abnormal baPWV. Although the biological mechanism behind it is not well understood, the different effects of soybean intake on baPWV depending on different genotypes of rs107251 suggest that a soybean-rich diet might not be beneficial for everyone. After stratification by gender, significant interaction was observed only in male participants, which further implies that the role of soybean for males and females is different [49].

The strengths and potential limitation of the current study merit consideration. It is a relatively large study in a Chinese population with the measurement of inflammatory-related SNPs, the assessment of soybean consumption, other related dietary and lifestyle factors and baPWV. This allows us to explore not only the individual associations between the genetic or dietary risk factors and abnormal baPWV, 
but also the interactions of these risk factors for the surrogate marker of atherosclerosis. The study was carried out in a northern Chinese Han population, which greatly reduces the genetic heterogeneity. To improve data quality, the dietary and life style questionnaires were completed through the interviewer-administered method.

This study had some limitations. Firstly, given the fact that the study was a case-control design, results involving the dietary risk factors may be biased due to confounding; Secondly, although the food frequency questionnaire used in this study has been validated [50], measurement errors in food consumption are inevitable; Thirdly, total energy intake cannot be calculated in this study. However, logistic regressions involving soybean intake were all adjusted for other diet factors, which can partially reduce the influence on the results; Fourthly, the main effects of rs12495941 and rs107251 for baPWV were not validated in another independent dataset, so the results should be evaluated in larger epidemiology studies; Fifthly, factors like serum albumin and C-reactive protein may also affect baPWV, but were not assessed in this study; Finally, only 16 SNPs located on nine inflammation-related genes were selected based on literature reviews of their previously published associations with atherosclerosis and their potential biological functions. Thus, we cannot rule out the possibility that there might be other SNPs that interact with soybean intake and that can better explain the interactions observed in this study.

\section{Experimental Section}

\subsection{Subjects}

This community-based, cross-sectional study was conducted in Fangshan (a suburban district located in the southwest of Beijing, China). Three towns representing 3 different topographical areas (mountain, hill and plateau) within the district were selected for recruitment, for the socio-economic levels and medical conditions differ among these areas. The inclusion criteria for participants were as follows: (1) age $\geq 40$ years old; (2) capable of cooperating during physical examinations. The exclusion criteria were as follow: (1) ethnic group was not Han; (2) not a permanent resident. 2049 participants completed baPWV measurement and diet investigation, among which 256 refused to give blood samples, 44 were excluded for the differences between their left side and right side baPWVs being more than $500 \mathrm{~cm} / \mathrm{s}$, which might be an indicator for artery occlusion. At last 1749 subjects were included in the analysis of this study.

\section{2. baPWV Measurement}

baPWV was measured by trained medical staff using automatic devices (BP-203PRE-III, Colin, Japan). After a participant lied down for $3 \mathrm{~min}, 4$ blood pressure cuffs were bound to the upper limbs and ankles. The pulse waves of four limbs were automatically recorded using oscillography. PWV was calculated by dividing the distance between two measuring points by the time difference of pulse waves of two points. This method was proven to have high reliability and validity [51]. In this study, the mean of left side and right side baPWVs was taken as one's final baPWV. The binary baPWV outcome was generated by using the cutoff point of $1700 \mathrm{~cm} / \mathrm{s}$ for predicting cardiovascular events 
suggested by Tomiyama et al. [52], i.e., baPWV $\geq 1700 \mathrm{~cm} / \mathrm{s}$ was defined as abnormal baPWV in this study.

\subsection{Measurement of Soybean Consumption and Other Dietary Factors}

The food intake questionnaire used in this study was a shortened version of the FFQ from Shanghai Women's Health Study (SWHS). The validity and reproducibility of the FFQ was reported elsewhere [50]. The food list was revised based on the dietary habits of Beijing rural residents, including the items of cereal foods, vegetables, fruit, egg, milk and soybean. During the face-to-face surveys, subjects were first asked at which frequency level they consumed each food (feasible choices including daily, weekly, monthly, yearly or never). Questions of how many times at each level they consumed these foods and the average amount of consumption per time followed. A standard portion size measured in liang ( 1 liang $=50 \mathrm{~g}$ ), a weight unit commonly used in China, was specified for each food (e.g., bowl, glass, serving). According to the recorded frequency and amount of food intake per time, the average weekly intake amount for soybean and average daily intake amount for other dietary factors were calculated. Diet factors were dichotomized by their median intake amount.

\subsection{Anthropometric and Biochemical Indices Determinations}

Demographic information was collected by a standard questionnaire. Surveys were carried out by trained and qualified staff. The definition of being a current smoker was having at least 1 cigarette per day and lasting for at least 6 months. The definition of a current drinker was having at least 50 milliliters of white spirits per week and lasting for at least 6 months. The weekly frequency and duration of moderate-intensity exercise were also asked.

Anthropometric variables, such as weight and height, were measured by trained doctors and nurses. After being calmed down for $5 \mathrm{~min}$, sitting blood pressure was examined 3 times by brachial blood pressure meters (HEM-7200, Omron Healthcare, Kyoto, Japan). The mean of the second and the third observed values was taken as one's final blood pressure. BMI was calculated as weight $/ \mathrm{height}^{2}\left(\mathrm{~kg} / \mathrm{m}^{2}\right)$.

Participants were asked to fast at least for $8 \mathrm{~h}$ before the collection of blood samples. Fasting venous blood was drawn for genotyping and biochemical indices measurements. All blood samples were tested at Peking University Health Science Center Key Laboratory of Epidemiology for fasting blood glucose (FBG), total cholesterol (TC), total triglycerides (TG), high-density lipoprotein cholesterol (HDL-C) and low-density lipoprotein cholesterol (LDL-C).

\subsection{Genotyping of SNPS}

DNA was extracted from peripheral blood leucocytes. Inflammatory-related SNPs were selected using the literature review method. Genotyping of rs182052, rs12495941, rs6565105, rs1048612, rs3865188, rs3825075, rs107251, rs2293050, rs2297630, rs1801157, rs2228014, rs662, rs3735590, rs1333040, rs2383207 and rs2383206 was performed using time-of-flight mass spectrometry genotyping technology with a MassARRAY ${ }^{\circledR}$ genetic analysis system (Sequenom Inc., San Diego, CA, USA) following the manufacturer's protocol. Genotypes were assessed by MassARRAY ${ }^{\circledR}$ Typer Analyzer Version 4.0. The call rates for 16 SNPs were all above $99.5 \%$. 


\subsection{Statistical Analysis}

The distributions of SNPs were analyzed for deviation from Hardy-Weinberg equilibrium (HWE) using Pearson's $\chi^{2}$ test, and no violation was found for any SNP. HWE $p$-values for all SNPs are shown in Table 1. Dominant, recessive and additive genetic models were assumed for every SNP. For a polymorphism with two alleles (A and a, A was the risk allele), three genotypes (AA, Aa, aa) are to be tested for association. AA and Aa genotypes are pooled together in the dominant model, while Aa and aa genotypes are pooled together in the recessive model. The additive model indicates a linear relation between the number of risk allele and disease risk [53].

Continuous variables were described as the mean \pm standard deviation and the Student $t$-test was adopted to compare means across groups. Categorical variables were described as frequency and proportion, and Pearson's $\chi^{2}$ test was used to compare frequencies between groups.

Unconditional logistic regression (ULR) was performed to estimate the associations between baPWV and SNPs. All ORs were adjusted for variables proven to be associated with baPWV or atherosclerosis previously, including age, gender, smoking status, drinking status, BMI, FBG, systolic blood pressure (SBP), TG and HDL-C. To estimate the interaction effect, a multiplicative term of two variables was included in the regression model. The data were analyzed using SPSS Version 16.0 for windows (SPSS Inc., Chicago, IL, USA).

Statistical power for the interactions between rs107251, rs12495941 and soybean intake was calculated by QUANTO 1.2.4 (Available online: http://hydra.usc.edu/gxe). The statistical power based on the current sample size was over $80 \%$.

\subsection{Ethics Statement}

The study design was explained to every subject during recruitment. Every participant gave written informed consent. This project was approved by the Ethics Committee of Peking University Health Science Center, Beijing, China.

\section{Conclusions}

Among 16 inflammatory-related SNPs located on ADIPOQ, CDH13, SIRT3, SIRT6, NOS1, CXCL12, CXCR4, PON1 and CDKN2B, ADIPOQ rs12495941 and SIRT6 rs107251 polymorphisms were associated with baPWV. An interaction between SIRT6 rs107251 and soybean intake for abnormally high baPWV was found. A low level of soybean intake can significantly decrease the risk of abnormal baPWV in individuals of rs107251 CT/TT genotypes, but not in those of the CC genotype. The results should be evaluated in larger epidemiology studies.

\section{Acknowledgments}

The authors thank the staff at Beijing Fangshan District Center for Disease Control for their help. This study was supported by the Key Project of Natural Science Funds of China (81230066) and the National Natural Science Fund Projects of China (81102177, 81172744). 


\section{Author Contributions}

Kexin Sun carried out the analysis and interpretation of data, and drafted the original manuscript; $\mathrm{Na} \mathrm{Li}$ and Shaoping Huang assisted in the organization of the survey; Xiao Xiang, Xueying Qin, Yiqun $\mathrm{Wu}$, Xun Tang and Tao $\mathrm{Wu}$ assisted in the detailed methods of this study; Jing Li conducted biochemical indices measurements and SNP genotyping experiments; Pei Gao reviewed the statistical analysis and revised the manuscript; and Dafang Chen and Yonghua Hu conceived the study. All authors approved the final version of the article, including the authorship list.

\section{Conflicts of Interest}

The authors declare no conflict of interest.

\section{References}

1. Bramwell, J.C.; Hill, A. Velocity of transmission of the pulse-wave: And elasticity of arteries. Lancet 1922, 199, 891-892.

2. O’Rourke, M.F.; Mancia, G. Arterial stiffness. J. Hypertens. 1999, 17, 1-4.

3. Blacher, J.; Asmar, R.; Djane, S.; London, G.M.; Safar, M.E. Aortic pulse wave velocity as a marker of cardiovascular risk in hypertensive patients. Hypertension 1999, 33, 1111-1117.

4. Epstein, F.H.; Ross, R. Atherosclerosis-An inflammatory disease. N. Engl. J. Med. 1999, 340, $115-126$.

5. Hansson, G.K. Inflammation, atherosclerosis, and coronary artery disease. N. Engl. J. Med. 2005, 352, 1685-1695.

6. Stone, G.W.; Maehara, A.; Lansky, A.J.; de Bruyne, B.; Cristea, E.; Mintz, G.S.; Mehran, R.; McPherson, J.; Farhat, N.; Marso, S.P.; et al. A prospective natural-history study of coronary atherosclerosis. N. Engl. J. Med. 2011, 364, 226-235.

7. Angelovich, T.A.; Hearps, A.C.; Jaworowski, A. Inflammation-induced foam cell formation in chronic inflammatory disease. Immunol. Cell Biol. 2015, doi:10.1038/icb.2015.26.

8. McPherson, R.; Davies, R.W. Inflammation and coronary artery disease: Insights from genetic studies. Can. J. Cardiol. 2012, 28, 662-666.

9. McPherson, R.; Pertsemlidis, A.; Kavaslar, N.; Stewart, A.; Roberts, R.; Cox, D.R.; Hinds, D.A.; Pennacchio, L.A.; Tybjaerg-Hansen, A.; Folsom, A.R.; et al. A common allele on chromosome 9 associated with coronary heart disease. Science 2007, 316, 1488-1491.

10. Helgadottir, A.; Thorleifsson, G.; Manolescu, A.; Gretarsdottir, S.; Blondal, T.; Jonasdottir, A.; Jonasdottir, A.; Sigurdsson, A.; Baker, A.; Palsson, A.; et al. A common variant on chromosome 9p21 affects the risk of myocardial infarction. Science 2007, 316, 1491-1493.

11. Samani, N.J.; Erdmann, J.; Hall, A.S.; Hengstenberg, C.; Mangino, M.; Mayer, B.; Dixon, R.J.; Meitinger, T.; Braund, P.; Wichmann, H.E.; et al. Genomewide association analysis of coronary artery disease. N. Engl. J. Med. 2007, 357, 443-453.

12. Hu, E.; Liang, P.; Spiegelman, B.M. $A D I P O Q$ is a novel adipose-specific gene dysregulated in obesity. J. Biol. Chem. 1996, 271, 10697-10703. 
13. Ouchi, N.; Kihara, S.; Funahashi, T.; Matsuzawa, Y.; Walsh, K. Obesity, adiponectin and vascular inflammatory disease. Curr. Opin. Lipidol. 2003, 14, 561-566.

14. Wassel, C.L.; Pankow, J.S.; Rasmussen-Torvik, L.J.; Li, N.; Taylor, K.D.; Guo, X.; Goodarzi, M.O.; Palmas, W.R.; Post, W.S. Associations of SNPs in $A D I P O Q$ and subclinical cardiovascular disease in the multi-ethnic study of atherosclerosis (MESA). Obesity 2011, 19, 840-847.

15. Hug, C.; Wang, J.; Ahmad, N.S.; Bogan, J.S.; Tsao, T.S.; Lodish, H.F. T-cadherin is a receptor for hexameric and high-molecular-weight forms of Acrp30/adiponectin. Proc. Natl. Acad. Sci. USA 2004, 101, 10308-10313.

16. Takeuchi, T.; Adachi, Y.; Ohtsuki, Y.; Furihata, M. Adiponectin receptors, with special focus on the role of the third receptor, T-cadherin, in vascular disease. Med. Mol. Morphol. 2007, 40, $115-120$.

17. Imai, S.; Armstrong, C.M.; Kaeberlein, M.; Guarente, L. Transcriptional silencing and longevity protein Sir2 is an nad-dependent histone deacetylase. Nature 2000, 403, 795-800.

18. Liu, G.; Cao, M.; Xu, Y.; Li, Y. Sirt3 protects endothelial cells from high glucose-induced cytotoxicity. Int. J. Clin. Exp. Pathol. 2015, 8, 353-360.

19. Webster, K.A. A sirtuin link between metabolism and heart disease. Nat. Med. 2012, 18, 1617-1619.

20. Sundaresan, N.R.; Vasudevan, P.; Zhong, L.; Kim, G.; Samant, S.; Parekh, V.; Pillai, V.B.; Ravindra, P.V.; Gupta, M.; Jeevanandam, V.; et al. The sirtuin SIRT6 blocks IGF-Akt signaling and development of cardiac hypertrophy by targeting c-Jun. Nat. Med. 2012, 18, 1643-1650.

21. Kugel, S.; Mostoslavsky, R. Chromatin and beyond: The multitasking roles for SIRT6. Trends Biochem. Sci. 2014, 39, 72-81.

22. Zernecke, A.; Shagdarsuren, E.; Weber, C. Chemokines in atherosclerosis: An update. Arterioscler. Thromb. Vasc. Biol. 2008, 28, 1897-1908.

23. Breton, C.V.; Park, C.; Siegmund, K.; Gauderman, W.J.; Whitfield-Maxwell, L.; Hodis, H.N.; Avol, E.; Gilliland, F.D. NOS1 methylation and carotid artery intima-media thickness in children. Circ. Cardiovasc. Genet. 2014, 7, 116-122.

24. Liu, T.; Zhang, X.; Zhang, J.; Liang, Z.; Cai, W.; Huang, M.; Yan, C.; Zhu, Z.; Han, Y. Association between PON1 rs662 polymorphism and coronary artery disease. Eur. J. Clin. Nutr. 2014, 68, 1029-1035.

25. Madssen, E.; Videm, V.; Moholdt, T.; Wisloff, U.; Hegbom, K.; Wiseth, R. Predictors of beneficial coronary plaque changes following aerobic exercise. Med. Sci. Sports Exerc. 2015, in press.

26. Van Bussel, B.C.; Henry, R.M.; Ferreira, I.; van Greevenbroek, M.M.; van der Kallen, C.J.; Twisk, J.W.; Feskens, E.J.; Schalkwijk, C.G.; Stehouwer, C.D. A healthy diet is associated with less endothelial dysfunction and less low-grade inflammation over a 7-year period in adults at risk of cardiovascular disease. J. Nutr. 2015, 145, 532-540.

27. Yamori, Y. Food factors for atherosclerosis prevention: Asian perspective derived from analyses of worldwide dietary biomarkers. Exp. Clin. Cardiol. 2006, 11, 94-98.

28. Cortez-Cooper, M.Y.; Supak, J.A.; Tanaka, H. A new device for automatic measurements of arterial stiffness and ankle-brachial index. Am. J. Cardiol. 2003, 91, 1519-1522.

29. Kobayashi, K.; Akishita, M.; Yu, W.; Hashimoto, M.; Ohni, M.; Toba, K. Interrelationship between non-invasive measurements of atherosclerosis: Flow-mediated dilation of brachial artery, carotid intima-media thickness and pulse wave velocity. Atherosclerosis 2004, 173, 13-18. 
30. Ong, K.L.; Li, M.; Tso, A.W.; Xu, A.; Cherny, S.S.; Sham, P.C.; Tse, H.F.; Lam, T.H.; Cheung, B.M.; Lam, K.S. Association of genetic variants in the adiponectin gene with adiponectin level and hypertension in hong kong chinese. Eur. J. Endocrinol. 2010, 163, 251-257.

31. Shi, H.; Lu, Y.; Du, J.; Du, W.; Ye, X.; Yu, X.; Ma, J.; Cheng, J.; Gao, Y.; Cao, Y.; et al. Application of back propagation artificial neural network on genetic variants in adiponectin $A D I P O Q$, peroxisome proliferator-activated receptor- $\gamma$, and retinoid $\mathrm{x}$ receptor- $\alpha$ genes and type 2 diabetes risk in a chinese han population. Diabetes Technol. Ther. 2012, 14, 293-300.

32. Sanghera, D.K.; Demirci, F.Y.; Been, L.; Ortega, L.; Ralhan, S.; Wander, G.S.; Mehra, N.K.; Singh, J.; Aston, C.E.; Mulvihill, J.J.; et al. PPARG and ADIPOQ gene polymorphisms increase type 2 diabetes mellitus risk in asian indian Sikhs: Pro12Ala still remains as the strongest predictor. Metabolism 2010, 59, 492-501.

33. Liszt, G.; Ford, E.; Kurtev, M.; Guarente, L. Mouse Sir2 homolog SIRT6 is a nuclear ADP-ribosyltransferase. J. Biol. Chem. 2005, 280, 21313-21320.

34. Zhong, L.; D'Urso, A.; Toiber, D.; Sebastian, C.; Henry, R.E.; Vadysirisack, D.D.; Guimaraes, A.; Marinelli, B.; Wikstrom, J.D.; Nir, T.; et al. The histone deacetylase SIRT6 regulates glucose homeostasis via HIF1 $\alpha$. Cell 2010, 140, 280-293.

35. Kim, H.S.; Xiao, C.; Wang, R.H.; Lahusen, T.; Xu, X.; Vassilopoulos, A.; Vazquez-Ortiz, G.; Jeong, W.I.; Park, O.; Ki, S.H.; et al. Hepatic specific disruption of SIRT6 in mice results in fatty liver formation due to enhanced glycolysis and triglyceride synthesis. Cell Metab. 2010, 12, 224-236.

36. Yao, Q.P.; Zhang, P.; Qi, Y.X.; Chen, S.G.; Shen, B.R.; Han, Y.; Yan, Z.Q.; Jiang, Z.L. The role of SIRT6 in the differentiation of vascular smooth muscle cells in response to cyclic strain. Int. J. Biochem. Cell Biol. 2014, 49, 98-104.

37. TenNapel, M.J.; Lynch, C.F.; Burns, T.L.; Wallace, R.; Smith, B.J.; Button, A.; Domann, F.E. SIRT6 minor allele genotype is associated with $>5$-year decrease in lifespan in an aged cohort. PLOS ONE 2014, 9, e115616.

38. Dong, C.; Della-Morte, D.; Wang, L.; Cabral, D.; Beecham, A.; McClendon, M.S.; Luca, C.C.; Blanton, S.H.; Sacco, R.L.; Rundek, T. Association of the sirtuin and mitochondrial uncoupling protein genes with carotid plaque. PLoS ONE 2011, 6, e27157.

39. Maeda, S.; Koya, D.; Araki, S.-I.; Babazono, T.; Umezono, T.; Toyoda, M.; Kawai, K.; Imanishi, M.; Uzu, T.; Suzuki, D. Association between single nucleotide polymorphisms within genes encoding sirtuin families and diabetic nephropathy in Japanese subjects with type 2 diabetes. Clin. Exp. Nephrol. 2011, 15, 381-390.

40. Rosenson, R.S.; Fioretto, P.; Dodson, P.M. Does microvascular disease predict macrovascular events in type 2 diabetes? Atherosclerosis 2011, 218, 13-18.

41. Wei, P.; Liu, M.; Chen, Y.; Chen, D.-C. Systematic review of soy isoflavone supplements on osteoporosis in women. Asian Pac. J. Trop. Med. 2012, 5, 243-248.

42. Huang, C.C.; Hsu, B.Y.; Wu, N.L.; Tsui, W.H.; Lin, T.J.; Su, C.C.; Hung, C.F. Anti-photoaging effects of soy isoflavone extract (aglycone and acetylglucoside form) from soybean cake. Int. J. Mol. Sci. 2010, 11, 4782-4795.

43. Kao, T.H.; Huang, R.F.S.; Chen, B.H. Antiproliferation of hepatoma cell and progression of cell cycle as affected by isoflavone extracts from soybean cake. Int. J. Mol. Sci. 2007, 8, 1095-1110. 
44. Wang, Q.; Li, H.; Tao, P.; Wang, Y.P.; Yuan, P.; Yang, C.X.; Li, J.Y.; Yang, F.; Lee, H.; Huang, Y. Soy isoflavones, CYP1A1, CYP1B1, and COMT polymorphisms, and breast cancer: A case-control study in southwestern china. DNA Cell Biol. 2011, 30, 585-595.

45. Xu, W.H.; Zheng, W.; Cai, Q.; Cheng, J.R.; Cai, H.; Xiang, Y.B.; Shu, X.O. The Asp(327)Asn polymorphism in the sex hormone-binding globulin gene modifies the association of soy food and tea intake with endometrial cancer risk. Nutr. Cancer 2008, 60, 736-743.

46. Deming, S.L.; Zheng, W.; Xu, W.H.; Cai, Q.; Ruan, Z.; Xiang, Y.B.; Shu, X.O. UGT1A1 genetic polymorphisms, endogenous estrogen exposure, soy food intake, and endometrial cancer risk. Cancer Epidemiol. Biomark. Prev. 2008, 17, 563-570.

47. Wang, J.W.; Tang, X.; Li, N.; Wu, Y.Q.; Li, S.; Li, J.; Qin, X.Y.; Zhang, Z.X.; Hu, Y.H.; Chen da, F. The impact of lipid-metabolizing genetic polymorphisms on body mass index and their interactions with soybean food intake: A study in a chinese population. Biomed. Environ. Sci. 2014, 27, 176-185.

48. Serrano, J.C.; de Lorenzo, D.; Cassanye, A.; Martin-Gari, M.; Espinel, A.; Delgado, M.A.; Pamplona, R.; Portero-Otin, M. Vitamin D receptor BSMI polymorphism modulates soy intake and 25-hydroxyvitamin d supplementation benefits in cardiovascular disease risk factors profile. Genes Nutr. 2013, 8, 561-569.

49. Kuiper, G.G.; Lemmen, J.G.; Carlsson, B.; Corton, J.C.; Safe, S.H.; van der Saag, P.T.; van der Burg, B.; Gustafsson, J.A. Interaction of estrogenic chemicals and phytoestrogens with estrogen receptor $\beta$. Endocrinology 1998, 139, 4252-4263.

50. Shu, X.O.; Yang, G.; Jin, F.; Liu, D.; Kushi, L.; Wen, W.; Gao, Y.T.; Zheng, W. Validity and reproducibility of the food frequency questionnaire used in the shanghai women's health study. Eur. J. Clin. Nutr. 2004, 58, 17-23.

51. Yamashina, A.; Tomiyama, H.; Takeda, K.; Tsuda, H.; Arai, T.; Hirose, K.; Koji, Y.; Hori, S.; Yamamoto, Y. Validity, reproducibility, and clinical significance of noninvasive brachial-ankle pulse wave velocity measurement. Hypertens. Res. 2002, 25, 359-364.

52. Tomiyama, H.; Koji, Y.; Yambe, M.; Shiina, K.; Motobe, K.; Yamada, J.; Shido, N.; Tanaka, N.; Chikamori, T.; Yamashina, A. Brachial-Ankle pulse wave velocity is a simple and independent predictor of prognosis in patients with acute coronary syndrome. Circ. J. 2005, 69, 815-822.

53. Lewis, C.M. Genetic association studies: Design, analysis and interpretation. Brief. Bioinform. 2002, 3, 146-153.

(C) 2015 by the authors; licensee MDPI, Basel, Switzerland. This article is an open access article distributed under the terms and conditions of the Creative Commons Attribution license (http://creativecommons.org/licenses/by/4.0/). 